http://jmscr.igmpublication.org/home/

ISSN (e)-2347-176x ISSN (p) 2455-0450

crossref DOI: https://dx.doi.org/10.18535/jmscr/v8i2.58

\title{
Unusual Metastasis to Thyroid from Minor Salivary gland Carcinoma
}

\author{
Authors \\ Dr Milap Shah, Dr Palak Jain, Dr Sai Sindhu, Dr Pooja, Dr Archana, Dr Sarika \\ Department of Pathology, Yashoda Hospital Secunderabad
}

\begin{abstract}
Metastases to thyroid is extremely unusual and most common primary cancer to metastasize to the thyroid is renal followed by malignancies of the gastrointestinal tract, lungs, breast and skin. Metastasis from minor salivary gland carcinoma is extremely rare with only few case reports found after extensive pubmed search. Most of the cases were found to be direct extension from tracheal or laryngeal minor salivary gland carcinoma. We present two cases of already diagnosed case of salivary gland carcinoma now presented with thyroid lesion: One is of Adenoid cystic carcinoma of Bronchus in 61 year old male diagnosed and operated in 2009, now in May 2017 he presented with nodule in upper pole of Left lobe of thyroid. On USG well defined lobulated hypoechoic lesion measuring $38 x 20 \times 25$ seen. Patient underwent total thyrodectomy and histomorphology and ihc profile (P63 and SMA positivity with PAX 8 and ttfl negativity) confirm diagnosis of Adenoid Cystic carcinoma. Another case is of 45 year old male diagnosed case of Polymorphus low grade adenocarcinoma of base tongue, underwent Near total glossectomy with bilateral selective neck dissection in 2014. He presented with firm nodule in left lobe of thyroid in February 2018. On USG nodule is $18 \times 13 \times 15 \mathrm{~mm}$ heterogenous lesion with partly circumscribed and partly ill-defined margins. Patient underwent Total thyroidectomy with bilateral selective dissection and specimen showing main bulk of the tumour within left lobe of thyroid gland with minimal extra thyroidal extension. Histopathology and immunohistochemistry (CK7 and P63 positivity and PAX8 and 40 negativity) confirmed metastases to thyroid by salivary gland carcinoma.

Keywords: Salivary gland carcinoma, Thyroid metastasis, Adenoid Cystic Carcinoma (ACC), Polymorphous low grade adenocarcinoma (PLGA).
\end{abstract}

\section{Introduction}

Metastases to the thyroid gland from a non-thyroid primary are very uncommon and are mostly from the kidney, followed by gastrointestinal tract, lungs, skin, and rarely breast. ${ }^{(1-5)}$ Metastatic deposits in thyroid gland in an autopsy series reported an incidence of $0.5 \%-24 \% .^{(6,7)}$ Thyroidectomies for malignancies have yielded only $1.25 \%$ of metastatic lesions. ${ }^{(7)}$ Nakhjavani from Mayo clinic in 1966 opined metastasis to thyroid to portend poor prognosis. ${ }^{(8)}$
Metastasis from minor salivary gland carcinoma is extremely rare with only few case reports found after extensive pubmed search.

\section{Case Reports}

We present two cases of already diagnosed case of salivary gland carcinoma now presented with thyroid lesion, cytology was non conclusive for primary thyroid neoplasm in both the cases and both the patient underwent total thyroidectomy. 


\section{JMSCR Vol||08||Issue||02||Page 322-325||February}

\section{Case 1}

A 61 year old male diagnosed with salivary gland carcinoma of left bronchus was operated in 2009 for the same, histomorphology favoured diagnosis of adenoid cystic carcinoma which was confirmed by immunohistochemistry.

In May 2017 he presented with a nodule in upper pole of Left lobe of thyroid. Ultrasonography was done and was reported asa well defined lobulated hypoechoic lesion measuring $38 \times 20 \times 25 \mathrm{~mm}$. FNAC was done from the thyroid lesion and was reported as Bethesda category 6. Patient was advised for frozen evaluation for further diagnosis and management. Total thyroidectomy was done; grossly thyroid gland showed a greyish white firm nodule measuring $4 \times 3 \times 2 \mathrm{~cm}$ and Frozen section was reported as salivary gland carninoma. In view of frozen report bilateral neck node dissection was done as well. Extensive histopathological examination was done and showed a tumor comprising ductal and myoepithelial cells arranged in tubular and solid pattern. Perineural invasion was noted. Histomorphologyfavoured diagnosis of Adenoid cystic carcinoma. We further proceeded with immunohistochemistry to confirm the diagnosis. IHC showed tumor was positive for P63 and SMA and was negative for PAX8 and TTF1.

Histomorphology and IHC together ruled out primary thyroid malignancy and confirmed diagnosis of metastatic adenoid cystic carcinoma in a known case of adenoid cystic carcinoma of bronchus.

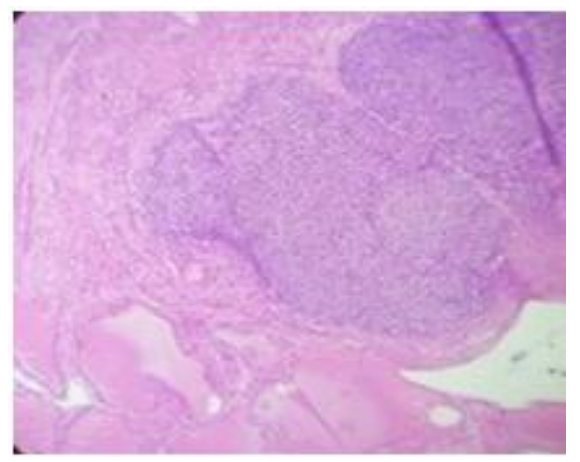

a 


\section{JMSCR Vol||08||Issue||02||Page 322-325||February}

with firm nodule in left lobe of thyroid in February 2018.On ultrasonographic evaltuation the nodule was reported as $18 \times 13 \times 15 \mathrm{~mm}$, heterogenous lesion with partly circumscribed and partly ill-defined margins. FNAC was done from the nodule and was reported as Bethesda category 6.Patient underwent Total thyroidectomy with bilateral selective neck dissection and specimen showed main bulk of the tumour within left lobe of thyroid gland with minimal extra thyroidal extension. Histopathological examination showed an infiltrative growth pattern with mixed architecture comprising of tubules, sheets and cribriforming. Cells have mild atypia but uniformly bland nuclei. Histology was suggestive of Polymorphous low grade adenocarcinoma. We further performed immunohistochemistry which revealed CK7 and P63 positivity and PAX8 and p40 negativity. Histomorphology and IHC confirmed metastases to thyroid by salivary gland carcinoma and clearly ruled out primary thyroid malignancy.

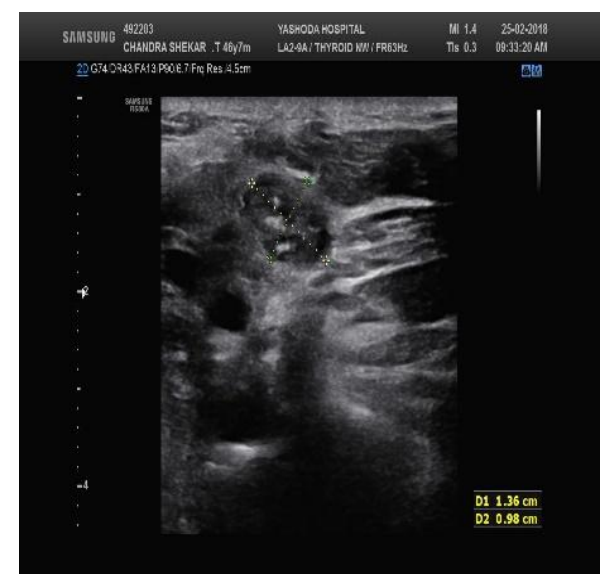

$\mathbf{a}$

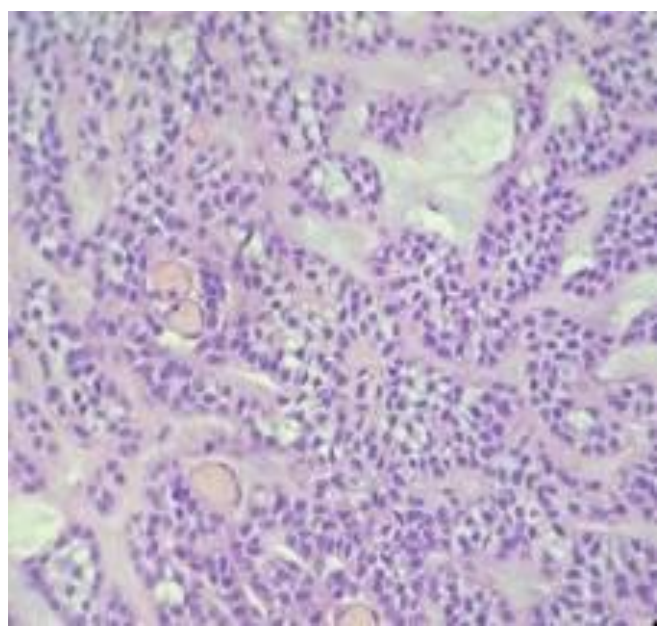

b

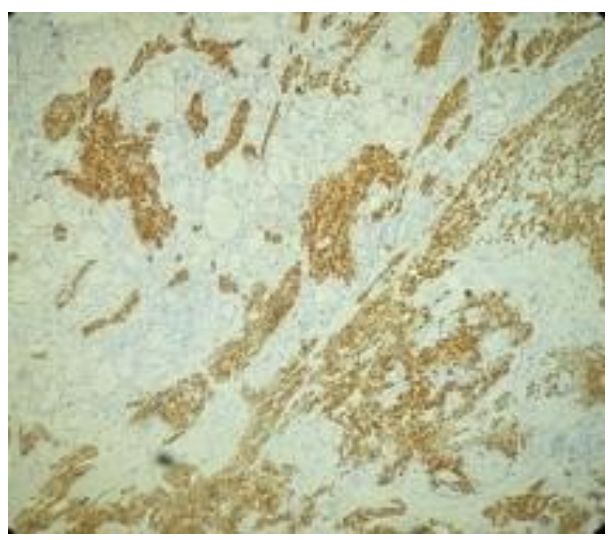

c

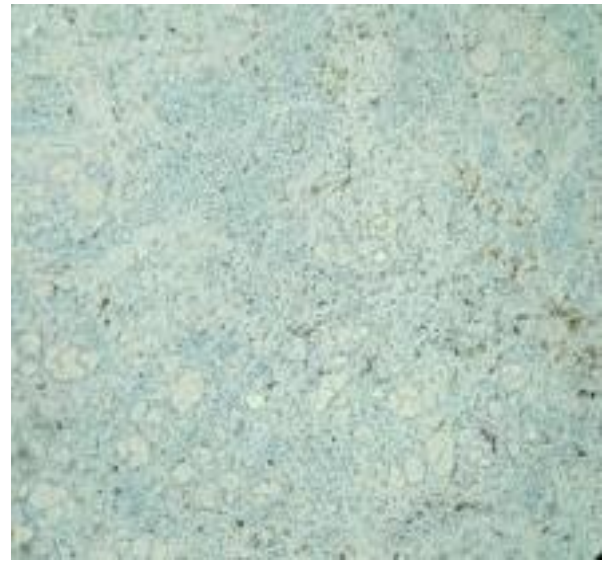

d

Figure 2 a) USG image showing thyroid nodule. b) Photomicrograph showing polymorphous low grade adenocarcinoma in thyroid gland $(\mathrm{H}$ and $\mathrm{E}$ $\mathrm{X} 200$ ) c) Tumour is diffusely positive for P63 and d) negative for TTF1 on immunohistochemistry.

\section{Discussion}

Thyroid metastases rarely cause symptoms. They may present as part of a widely disseminated disease process or may be the first manifestation of metastasis. ${ }^{(8)}$ The usual presentation is a solitary thyroid nodule and can cause symptoms of esophageal or tracheal compression with massive infiltration of the thyroid. Thyroid dysfunction in the form of hypo- or hyper-thyroidism is uncommon. The differential diagnoses include multinodular goiter, primary thyroid cancer such as anaplastic cancer, benign thyroid nodule, follicular dendritic cell tumor, poorly differentiated squamous carcinoma of thyroid, carcinoma showing thymus-like differentiation, and undifferentiated carcinoma. However, in a patient with a history of cancer, the 
nodule is most often malignant. ${ }^{(9)}$ FNAC is the most common method used to confirm the diagnosis. It is easy, cost-effective, and has high sensitivity, specificity, and negative predictive value $^{(10,11)}$. The intention of these case reports is to highlight the importance of past surgical history of the patient and how it helps to arrive at diagnosis which is sin qua non for appropriate management of patient.

\section{Conclusion}

Inspite of thyroid being a richly vascular organ metastasis to thyroid is a rare event as evidenced in many case reports and studies. Metastasis from a minor salivary gland carcinoma is even rarer. Accurate diagnosis of such rare possibilities requires thorough clinical, radiological, histopathological examination and correlation. As metastases to thyroid is poor prognostic factor there should be an appropriate diagnosis followed by immediate intervention for cure and palliation.

\section{References}

1. Moghaddam PA, Cornejo KM, Khan A. Metastatic carcinoma to the thyroid gland: a single institution 20-year experience and review of the literature. EndocrPathol. 2013;24:116-24.

2. Surov A, Machens A, Holzhausen HJ, Spielmann RP, Dralle H. Radiological features of metastases to the thyroid. ActaRadiol. 2016;57:444-50.

3. Mirallié E, Rigaud J, Mathonnet M, Gibelin H, Regenet N, Hamy A, Bretagnol F, de Calan L, Le Néel JC, Kraimps JL. Management and prognosis of metastases to the thyroid gland. J Am Coll Surg. 2005;200:203-7.

4. Hoo Kim K, Gaitor J, Lin O, Reid MD. Secondary tumors involving the thyroid gland: A multi-institutional analysis of 28 cases diagnosed on fine-needle aspiration. DiagnCytopathol. 2015;43:904-11
5. Hegerova L, Griebeler ML, Reynolds JP, Henry MR, Gharib H. Metastasis to the thyroid gland: report of a large series from the Mayo Clinic. Am J ClinOncol. 2015;38:338-42.

6. Lin JD, Weng HF, Ho YS. Clinical and pathological characteristics ofsecondary thyroid cancer. Thyroid 1998;8:149-53

7. Lam KY, Lo CY. Metastatic tumors of the thyroid gland: A study of 79 cases in chinese patients. Arch Pathol Lab Med 1998;122:37-41

8. Nakhjavani MK, Gharib H, Goellner JR, van Heerden JA. Metastasis to the thyroid gland. A report of 43 cases. Cancer 1997;79:574-8.

9. Wood K, Vini L, Harmer C. Metastases to the thyroid gland: The Royal Marsden experience. Eur J Surg Oncol 2004;30:583-8.

10. Muratli A, Erdogan N, Sevim S, Unal I, Akyuz S. Diagnostic efficacy and importance of fine-needle aspiration cytology of thyroid nodules. J Cytol 2014;31:73-8

11. Esmaili HA, Taghipour H. Fine-needle aspiration in the diagnosis of thyroid diseases: An appraisal in our institution. ISRN Pathology 2012: Article ID 912728:4 pages. 